Research Article

\title{
Phylogenetic relationships among Capuchin (Cebidae, Platyrrhini) lineages: An old event of sympatry explains the current distribution of Cebus and Sapajus
}

\author{
Antonio Marcio Gomes Martins-Junior ${ }^{1,2}$, Jeferson Carneiro ${ }^{1}$, Iracilda Sampaio ${ }^{1}$, Stephen F. Ferrari ${ }^{3,4}$ and \\ Horacio Schneider ${ }^{1}$ \\ ${ }^{1}$ Instituto de Estudos Costeiros, Universidade Federal do Pará, Bragança, PA, Brazil. \\ ${ }^{2}$ Laboratório de Genética, Evolução e Bioinformática, Instituto Federal do Pará, Tucurui, PA, Brazil. \\ ${ }^{3}$ Departamento de Ecologia, Universidade Federal de Sergipe, São Cristovão, SE, Brazil. \\ ${ }^{4}$ Department of Life Sciences, Roehampton University, London, UK.
}

\begin{abstract}
Capuchin monkeys are currently represented by four species of Cebus and eight of Sapajus. This group is taxonomically complex and several questions still need to be clarified. In the current study, using mtDNA markers and a larger sample representation than in previous studies, we seek to understand the phylogenetic relationships among the capuchin lineages and their historical biogeography. All 12 species of capuchins were analyzed for the mitochondrial Control Region and Cytochrome $b$ to test two biogeographical hypotheses: "Reinvasion of the Amazon (ROA)" and "Sympatric Evolution (SEV)". The phylogenetic relationships among distinct lineages within genera is consistent with an evolutionary diversification pattern probably resulting from an explosive process of diversification and dispersal between 2.0 Ma and 3.0 Ma. Also, the analyses show that the ancestral capuchins were distributed in a wide area encompassing the Amazon and Atlantic Forest. Our results support the SEV hypothesis, showing that the current syntopic distribution of Cebus and Sapajus can be explained by a sympatric speciation event in the Amazon. We also indicate that the recently proposed species taxonomy of Cebus is not supported, and that $S$. cay and $S$. macrocephalus are a junior synonym of $S$. apella.
\end{abstract}

Keywords: Capuchins, phylogeography, phylogeny, taxonomy, biogeography.

Received: January 16, 2017; Accepted: January 20, 2018.

\section{Introduction}

The taxonomy of capuchin monkeys (Cebus and Sapajus, Cebidae) is among the most controversial of Neotropical primates (Platyrrhini). Hershkovitz (1949) proposed four species, the gracile Cebus albifrons, Cebus nigrivittatus (= olivaceus) and Cebus capucinus, and the robust Cebus apella, with several subspecies. Groves (2001) elevated several these subspecies to valid species, i.e., Cebus libidinosus, Cebus xanthosternos and Cebus nigritus. Subsequent reviews (Silva Jr, 2001; Oliveira and Langguth, 2006) added five species, Cebus kaapori, Cebus macrocephalus, Cebus cay, Cebus flavius, and Cebus robustus. A new taxonomic proposal for the capuchins based on a genetic and morphological interpretation was recently presented by Alfaro et al. (2012) referring to Cebus for the gracile (or untufted) capuchins and Sapajus for the robust (or tufted) capuchins.

Send correspondence to Horacio Schneider. Instituto de Estudos Costeiros, Universidade Federal do Pará, Bragança, PA, Brazil. E-mail: horacio.schneider@gmail.com.
The gracile capuchins (Cebus spp.) are found from northern South America to southern Central America, whereas the robust capuchins (Sapajus spp.) are found throughout most of South America, as far south as northern Argentina (Figure 1). The two genera are sympatric throughout much of the Amazon basin (Silva Jr, 2001; Lynch Alfaro et al., 2012; IUCN, 2016). Currently four species of Cebus and eight of Sapajus are recognized (Silva Jr, 2001; Alfaro et al., 2012).

While some authors (Rosenberger, 2012; Feijó and Langguth, 2013) disagree with the Cebus-Sapajus division, Martins-Junior et al. (2015) supported this arrangement based on five nuclear loci, and there is a growing consensus about this taxonomic arrangement (Garbino, 2015; Schneider and Sampaio, 2015). However, the species diversity of the two genera and their origin and pattern of diversification continues to be discussed, and several species have been ressurected (Boubli et al., 2012; Rylands and Mittermeier, 2013).

A number of different geological and climatic factors have been identified as drivers of the diversification of the 

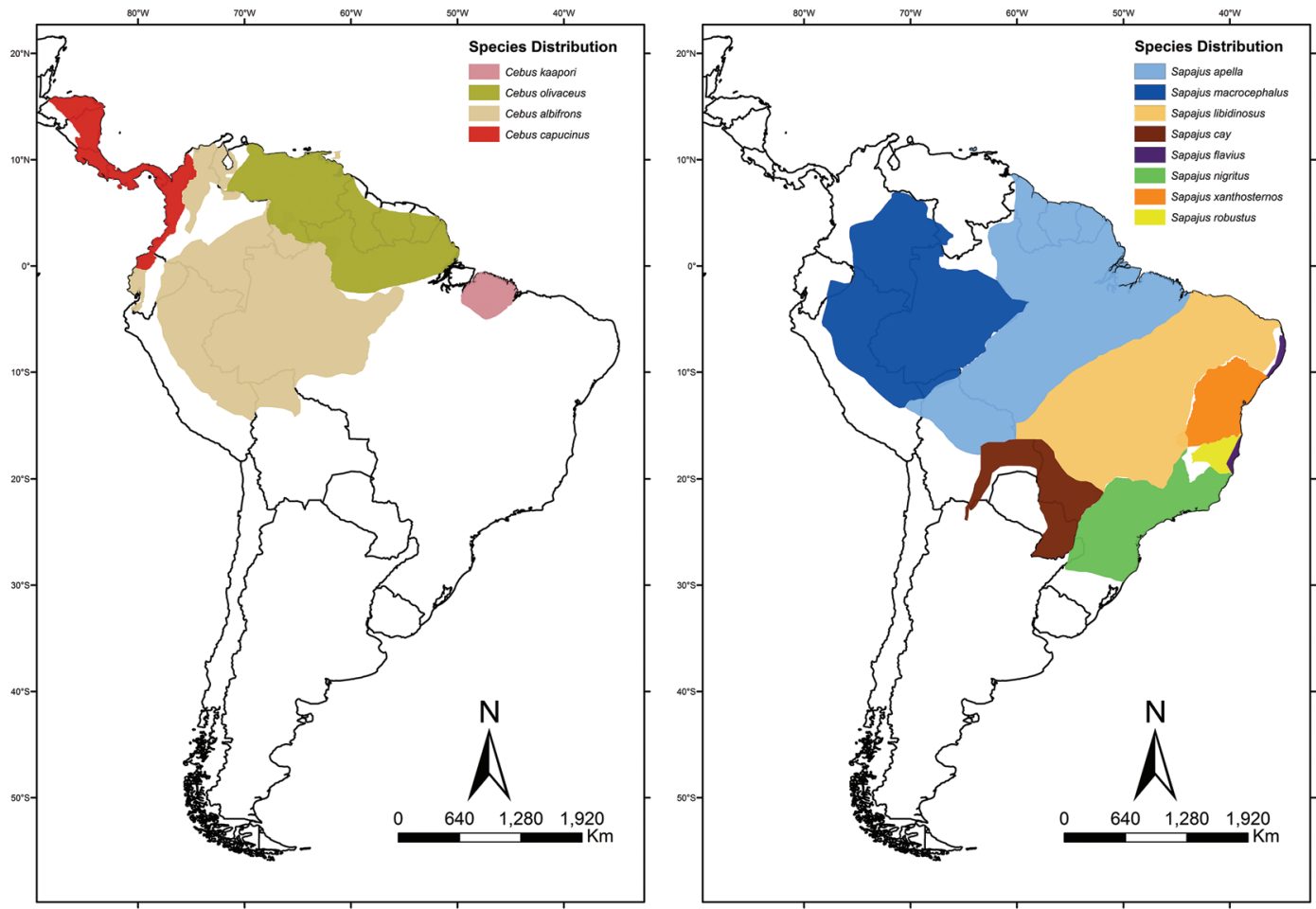

Figure 1 - Geographical distribution of robust (Sapajus) and gracile (Cebus) capuchins species. Map constructed based on information provided by Silva Jr (2001), Lynch Alfaro et al. (2012), and IUCN (2016).

present-day biota of South America (Haffer, 2008; Hoorn et al., 2010; Ribas et al., 2012), in particular the formation of forest refugia during different periods of the Pleistocene (Martins et al., 2009, 2011; de Thoisy et al., 2010; Ruiz-García et al., 2011). Over the past 25 years, however, a growing body of evidence (e.g., Nelson et al., 1990; Bush, 1994; Colinvaux et al., 2000; Rull, 2008) has contradicted the Pleistocene refugia hypothesis (Ashley and Vaughn, 1995; Ribas et al., 2005; Fuchs et al., 2011, 2015). At the same time, an increasing number of studies have reinforced the important role of Amazonian rivers as geographic barriers in the diversification of many vertebrate groups (Hayes and Sewlal, 2004; Ribas et al., 2012; Sousa-Neves et al., 2013), including primates (Vallinoto et al., 2006; Couette, 2007; Boubli et al., 2015; Lynch Alfaro et al., 2015; Mercês et al., 2015).

Lynch Alfaro et al. (2012) concluded that the capuchins originated in the western Amazon basin approximately 6.7 million years ago (Ma). In this scenario, Cebus would have arisen in the northern Amazon basin 2.1 Ma, and Sapajus in the Brazilian Atlantic Forest or Cerrado savanna at around $2.7 \mathrm{Ma}$. These authors interpret the current sympatry of the two genera as the result of the recent reinvasion of the Amazon basin by Sapajus from central Brazil, explained by their "Reinvasion of the Amazon (ROA)" hypothesis. Nascimento et al. (2015) challenged this interpretation based on the re-analysis of the data of Lynch Alfaro et al. (2012), concluding that the capuchins originated in the northern Atlantic Forest. And recently, Lima et al. (2017) using three mitochondrial markers (Cyt $b$, Control Region and a fragment of the Cytochrome Oxidase subunit I - COI), provided support the ROA hypothesis of the origin and distribution of the capuchin monkeys in South and Central America.

Given this, the current study aimed to provide a comprehensive analysis of the geographic origins and phylogenetic relationships of the capuchins through the sequencing of two mitochondrial genes, Cytochrome $b$ (Cyt $b$ ) and the Control Region in a broad geographic and taxonomic sample of capuchins. These two genes which have been used widely in studies of the evolution of Neotropical primates (Bonvicino et al., 2001; Cortés-Ortiz et al., 2003; Nascimento et al., 2005; Vallinoto et al., 2006; Casado et al., 2010; Babb et al., 2011; Matauschek et al., 2011; Boubli et al., 2012, 2015; Lynch Alfaro et al., 2012; Mercês et al., 2015).

The results obtained by Lynch Alfaro et al. (2012) and Lima et al. (2017) support vicariance, dividing ancestral capuchin populations in Amazonia versus the Atlantic Forest and a Pleistocene 'Amazonian invasion' by Sapajus to explain the present-day sympatry of Cebus and Sapajus. The present study intends to test this hypothesis against a new one proposed by us, which assumes that the common ancestor of all the capuchins occupied a wide distribution in different South American biomes (from the Amazon to the Atlantic Forest) and gave origin to extant Cebus and Sapajus by a sympatric speciation process. 


\section{Materials and Methods}

\section{Ethics statement}

This research adhered to the American Society of Primatologists' Principles for the Ethical Treatment of Primates.

\section{Sample collection and laboratory procedures}

Total DNA was extracted from blood, muscle and liver samples from 72 capuchin monkeys and purified in using the Wizard Genomic DNA Purification Kit
(Promega). Most of these specimens (65) were from wild, with the remaining seven specimens provided by the captive institutions (Figure 2, Table S1). All captive animals were identified based on their morphological characteristics.

About 600 bp of the mitochondrial Control Region (HVI region and $\sim 200 \mathrm{bp}$ of the initial portion of the d-loop region) and the Cyt $b$ gene - partial or complete - were amplified by PCR in a Verit 96 well thermocycler (Applied Biosystems). The Control Region PCR assays were carried out using primers for the Cebus Control Region L and Cebus Control Region R (Schneider et al., 2012). A portion

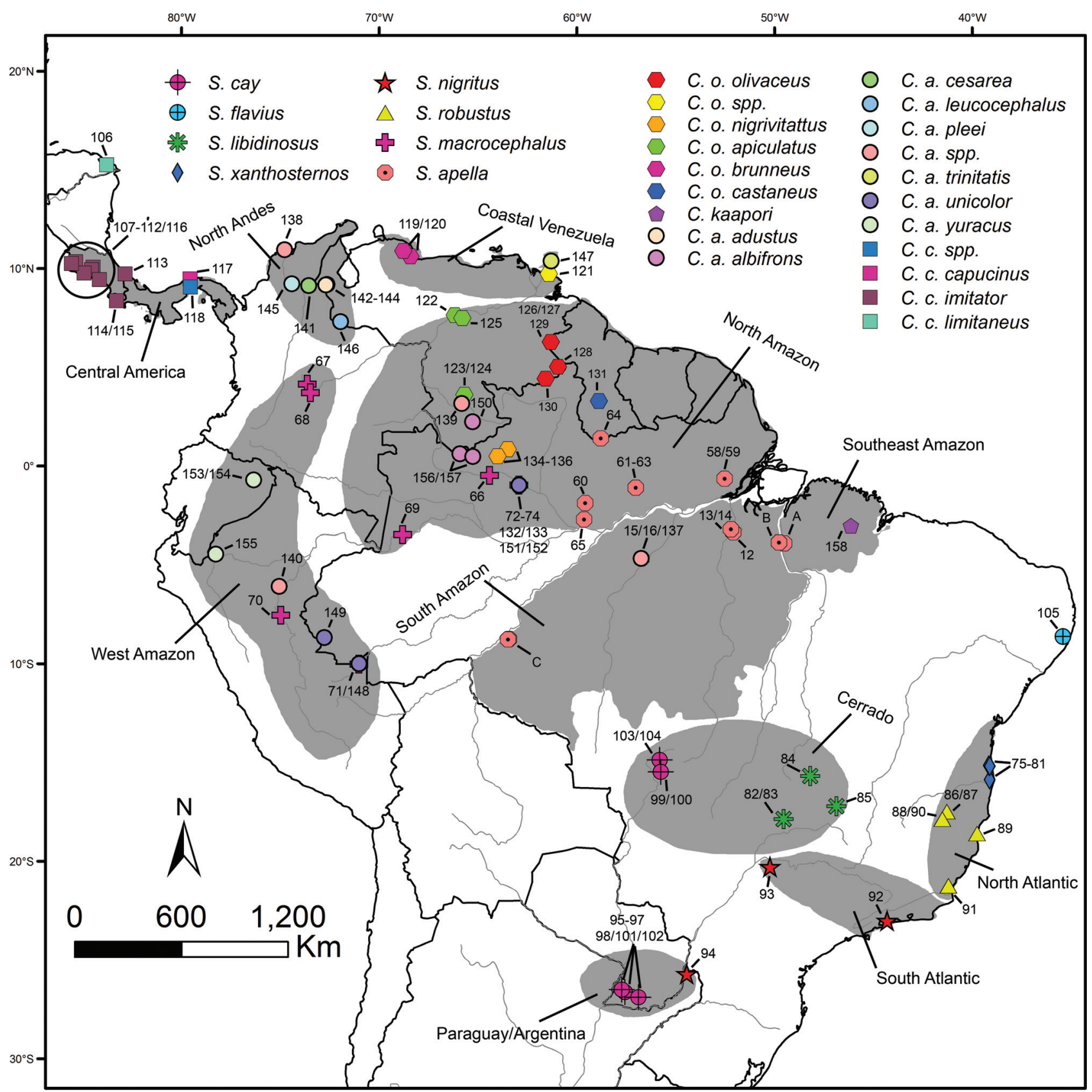

Figure 2 - Biogeographic zones analyzed (gray spots) and the collection sites of the Cebus and Sapajus samples. A = samples 1-4; B = samples 5-11; C= $17-57$. 
( $\sim 500$ bp in size) and the entire of Cyt $b$ gene were amplified using the primers Cytb1F and Cytb3R (Lynch Alfaro et al., 2012), and MVZ05 (Irwin et al., 1991) and MVZ16 (Smith and Patton, 1993), respectively. Preparation of the reactions and the PCR protocol were the same as described by Casado et al. (2010) for the Cyt $b$ gene and Schneider et al. (2012) for the Control Region. Amplification products were purified and then sequenced on an Applied Biosystems 3500 XL automatic Genetic Analyzer (Life Technologies).

To check for possible amplification of numts rather than true mtDNA, all sequences were submitted to the BLASTn and the Cyt $b$ sequences were translated. All sequences were deposited in the GenBank with codes from MF472455 to MF472591 (Table S1).

\section{Datasets, sequence alignment, model, and data partition selection}

In addition to the sequences produced in the current study, 45 Control Region and $80 \mathrm{Cyt} b$ gene sequences previously published by Casado et al. (2010), Oliveira et al. (2011), Boubli et al. (2012) and Lynch Alfaro et al. (2012) for capuchin monkeys were downloaded from GenBank. Sequences for different genera of Platyrrhini were also downloaded for these two mitochondrial markers.

Two datasets were used. The first dataset (DS1) was composed by 946 aligned cytochrome b mitochondrial DNA base pairs of 60 capuchin monkeys and 20 of other Neotropical primates, representing all three families (Cebidae, Atelidae and Pitheciidae), to estimate the crown age of capuchin monkeys and test monophyly. The second dataset (DS2) consisted of 1,481 base pairs of two mtDNA genes (Control Region and Cyt $b$ ), concatenated of 146 terminal taxa. All sequences were aligned by Clustal X (Larkin et al., 2007) with default parameters and manually checked in PhyDE $^{\circledR}$ (Müller et al., 2010).

To estimate the nucleotide substitution models and partitioning schemes that best fit each dataset, the PartitionFinder 1.1.1 (Lanfear et al., 2012) software was used. Selections were made using the Bayesian Information Criteria (BIC). In the specification of subsets of alignments, the Control Region locus was defined as a single data block and the Cyt $b$ gene was partitioned according with the three codon positions. All information about the datasets as length, number of samples, evolutionary models, etc. can be found in Table S2.

\section{Divergence time estimates among capuchin monkeys and other Platyrrhini main clades}

To estimate the crown age of capuchin monkeys, we used BEAST 1.8.3 (Drummond et al., 2012) software. Four calibration points based on four distinct Platyrrhini fossils were used: ${ }^{\dagger}$ Stirtonia, which provided a minimum age of 12.6 Ma (Hershkovitz, 1970; Kay et al., 1987) for crown Atelidae; ${ }^{\dagger}$ Proteropithecia (Kay et al., 1998), which provided a minimum age of 15.7 Ma for crown Pitheciidae;
${ }^{\dagger}$ Neosaimiri (Rosenberger et al., 1991; Takai, 1994) provided a minimum age of $12.5 \mathrm{Ma}$ for crown Cebinae; and ${ }^{\dagger}$ Lagonimico, which provided a minimum age of $13.4 \mathrm{Ma}$ for crown Callitrichinae (Kay, 1994).

The nodes were calibrated under a non-correlated lognormal relaxed molecular clock model. The split between Catarrhini and Platyrrhini ( $36 \mathrm{Ma})$ was used as the upper limit for the nodes calibrated under the lognormal distributions. The data was not partitioned and the $\mathrm{HKY}+\mathrm{I}+\mathrm{G}$ model was used, as selected by PartitionFinder 1.1.1 (Lanfear et al., 2012).

Four independent runs of MCMC were carried out with $100,000,000$ generations being sampled every 10,000 generations. The convergence of the chains and the ESS values for the different parameters were analyzed in the Tracer 1.6 software. The LogCombiner 1.8.3 software was used to combine the. $\log$ and trees files of the four independent runs. A burn-in of $10 \%$ was used and TreeAnnotatoor 1.8.3 software, was used to summarize all nodes and the a posteriori distributions of each parameter in a Maximum Clade Credibility (MCC) tree. The trees were visualized in FigTree 1.4.2.

\section{Phylogeographic analysis in capuchin monkeys}

To reconstruct the ancestral area and the biogeographical history of the main lineages of capuchin monkeys, the R package 'BioGeoBEARS' was used (Matzke, 2013, 2014). A consensus tree with one representative terminal of each main lineage of capuchin monkeys was built and used as "input" to the BioGeoBEARS analyses. The clade represented by the "arrow 3" (Figures 3 and 4) was set as a terminal, except for $S$. robustus.

According to the known geographical distribution for each capuchin species (Silva Jr, 2001; Rylands and Mittermeier, 2013), a pattern of presence/absence for each terminal was coded in a total of eight biogeographical areas, previously proposed by Lynch Alfaro et al. (2012) with minor modifications (Figure 2, Table S1): Atlantic Forest (AF) (composed by the North and South Atlantic), Cerrado (CE), Paraguay/Argentina (PA) (representing the Chaco), North Amazon (NM) (North Amazon + Coastal Venezuela), West Amazon (WM), North Andes/Central America $(\mathrm{CN})$, South Amazon (SM) and Southeast Amazon (SE).

All six models present in the 'BioGeoBEARS' package were tested to explain the biogeographical history of the capuchin monkeys: DEC, DEC-J, DIVALIKE, DIVALIKE-J, BAYAREALIKE, BAYAREALIKE-J. The choice of the best model was done checking the lower estimated AIC value.

In order to test whether the observed discrepancies (see Results and Discussion sections below) between our results and that of Lima et al. (2017) is due to the difference in the number of biogeographic areas, we ran the BioGeoBEARS program with the four areas proposed by these authors (see Methods Appendix S1). 


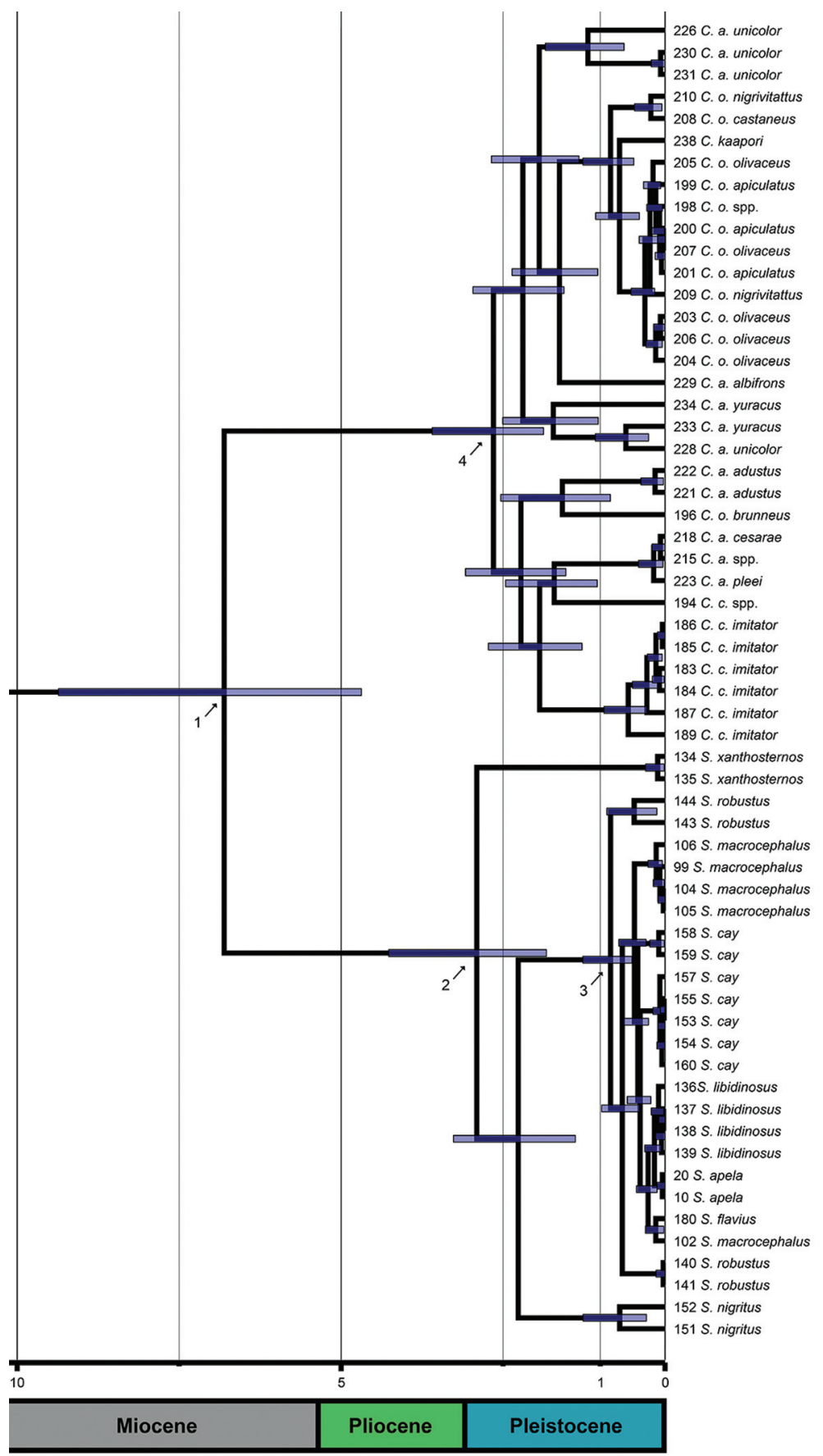

Figure 3 - Divergence time tree of capuchins estimated on BEAST 1.8.3. Nodes were calibrated using the age of four Platyrrhini fossils. The blue bars above the nodes indicate the Highest Posterior Density of the estimated ages. Arrows 1,2,3 and 4 represent the split of the crown capuchins, the first split of the crown Sapajus, a recent split within Sapajus ( 1.0 Ma) and the first split of the crown Cebus, respectively. The lower boxes indicate the geological times of the Cenozoic era.

\section{Phylogenetic inferences and estimates of divergence times}

Phylogenetic reconstructions were estimated based on three different criteria: Maximum Likelihood (ML), Bayesian Inference (BI), and Maximum Parsimony (MP). The RAxMLHPC-AVX 8.2.4 (Stamatakis, 2014) software was used to estimate ML trees, using the models and schemes shown in Table S2. A thousand searches for the most likelihood tree were made, using a random parsimony tree as the starting tree. Node support was provided per 1,000 pseudo replicates of bootstrap.

The MP analyses were carried out in TNT 1.5 beta (Goloboff et al., 2016) software. The New Technology tree search method was used through different search algo- 


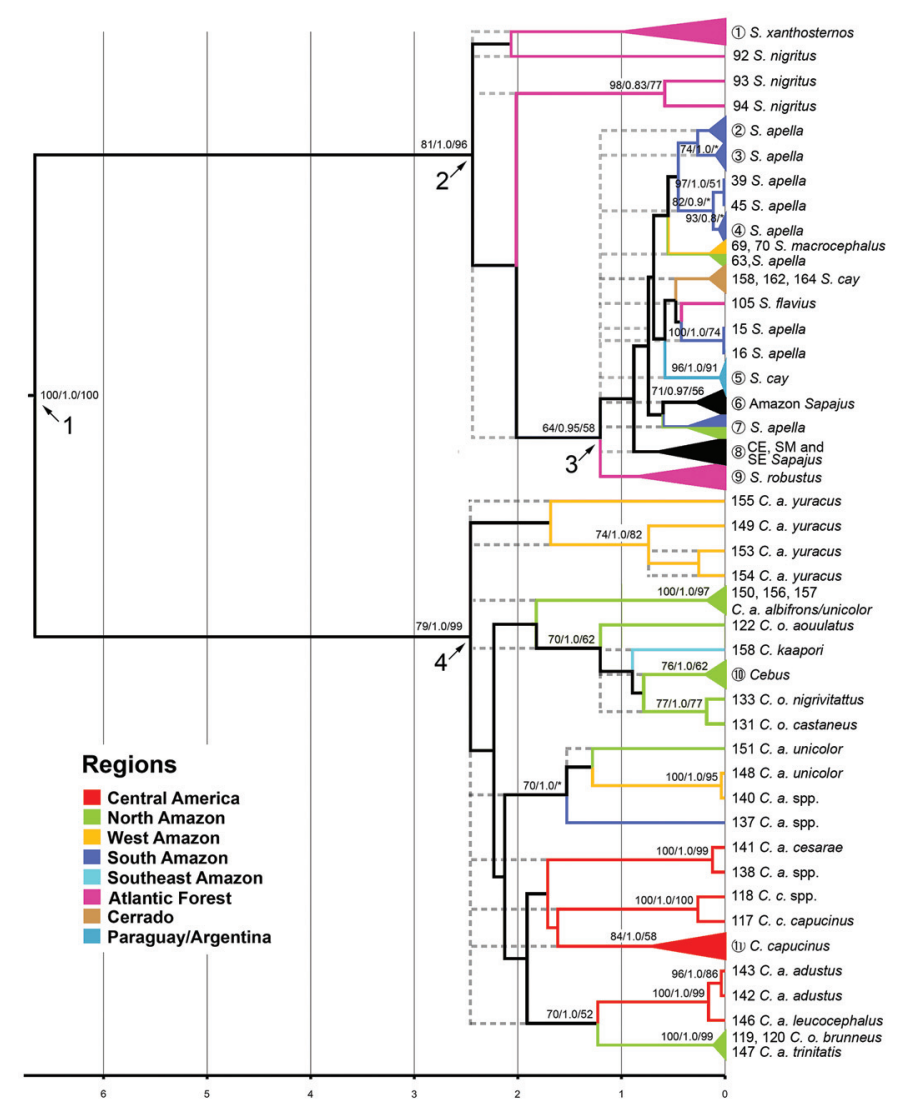

Figure 4 - Maximum Clade Credibility (MCC) gene tree estimated on BEAST 1.8.3 from DS2. Circles with Arabic numbers inside represent collapsed samples (see Table S1). The numbers above the nodes are statistical supports provided by, from left to right, Maximum Likelihood bootstrap, Bayesian credibility and Maximum Parsimony bootstrap. The dots show the polytomy in both genera. The meaning of arrows 1, 2, 3 and 4 is described in Figure 3 . Except for the nodes indicated by the arrows, only support values greater than $70 \%$ are shown.

rithms - RAS, TBR, Tree Drifting, Tree fusing, Ratchet and Sectorial Searches (random and constraint) (Goloboff, 1999). In each search, the best score value had to be found 1,000 times before stop. The support value of the nodes was provided by 1,000 pseudo replications of bootstrap using all the previously used search algorithms. Only bootstrap values above $90 \%$ were considered significant.

The BI analyses were carried out by four independent runs in the software BEAST 1.8.3 (Drummond et al., 2012). To estimate divergence times and phylogenetic relationships between different lineages of capuchin monkeys, a non-correlated lognormal relaxed molecular clock model was used to calibrate the tree through a uniform distribution of the crown age of the capuchin monkeys and their previously estimated 95\% HPDs (upper value $=9.36$; lower value $=4.69$ ). All other priors were set as default.

Four independent MCMC analyses for each dataset were run with $100,000,000$ generations being sampled for every 10,000 generations. To check the convergence of the chains and for building a Maximum Clade Credibility (MCC) gene tree, all procedures and softwares described in the previously section about divergence time estimates among capuchin monkeys and other Platyrrhini were used.

\section{Results}

\section{Sequences and numts}

A total of 137 new sequences were produced, 72 for the partial Control Region and 65 partial or total sequences of the Cyt $b$ gene. All Cyt $b$ sequences presented the typical open reading frame for this gene. BLASTn analysis confirmed the mitochondrial characteristics of the Cyt $b$ and Control Region sequences, confirming that they are composed of true mtDNA.

\section{Crown ages and phylogeny of the capuchins}

The crown age estimated for capuchins was approximately $6.8 \mathrm{Ma}$, that is, during the late Miocene (Table 1, Figures 3 and 4). The two databases agreed on a crown age for Sapajus ranging between the late Pliocene and early Pleistocene (Table 1), with ages varying from $2.44 \mathrm{Ma}$ (DS2) to $2.91 \mathrm{Ma}$ (DS1). Similarly, the inferences on divergence time indicate that Cebus began to diversify in the early Pleistocene, between 2.46 Ma (DS2) and 2.65 Ma (DS1).

The topologies recovered by the different phylogenetic criteria were broadly congruent (Figure 4). In all cases, monophyly of the capuchins had maximum statistical sup- 
Table 1 - Divergence times for capuchin monkeys and their HPD (Highest Posterior Density) intervals estimated from four different databases. Arrows 1, 2, 3 and 4 can be seen in Figures 3 and 4 .

\begin{tabular}{lcc}
\hline & TimeDS1 [HPD] & TimeDS2 [HPD] \\
\hline Arrow 1 (Capuchins) & $6.8[4.69-9.36]$ & $6.66[4.69-9.04]$ \\
Arrow 2 (Sapajus) & $2.91[1.83-4.27]$ & $2.44[1.38-3.79]$ \\
Arrow 3 & $0.84[0.51-1.27]$ & $1.2[0.71-1.87]$ \\
Arrow 4 (Cebus) & $2.65[1.88-3.59]$ & $2.46[1.49-3.73]$ \\
\hline
\end{tabular}

port, although the statistics were less conclusive for the monophyly of the genera Cebus and Sapajus (Figure 4). In Cebus, the BI and MP analyses confirmed the monophyly of the genus most emphatically, while ML provided an unsatisfactory value ( $B S=79$, Figure 4$)$. In the case of Sapajus, monophyly was supported by BI and MP analyses, while ML did not support it $(B S=81)$.

Some well-supported clades were also recovered within each genus, based on the different analyses, although these clades form a polytomy within the genera, impeding the recovery of monophyly or the phylogenetic relationships among the species (Figure 4).

The analyses recovered two clades in Sapajus, one formed by two S. nigritus samples (93 and 94), which did not group with the other specimen of the same species (92), and the other formed by the $S$. cay samples from the Paraguay/Argentina region (95-98 and 102), which did not group with the samples of the same species from the Brazilian Cerrado (Figure 4).

Despite the wide lack of statistical support for Sapajus, some insights are discussed. In all analyses, $S$. xanthosternos and "S. nigritus" were the first lineage to diversify in the early robust capuchin evolution. After that, all other robust capuchin lineages are grouped in a polytomy that diverged relatively recently $(\sim 0.8$ to $\sim 1.2 \mathrm{Ma})$ as indicated by arrow 3 in Figures 3 and 4, which has S. robustus as the first offshoot. Monophyly and the relationships among lineages in this clade could not be recovery with any kind of support.

Six distinct lineages were recovered for Cebus (Figure 4). One of these clades consisted of C. a. unicolor from the western Amazon (140 and 148). A second clade was formed by C. a. albifrons plus one sample of C. a. unicolor, also from the northern Amazon (150, 156 and 157), a third encompassed the subspecies C. a. cesarae (138 [C.a.spp.] and 141) from the northern Andes, a fourth, the northern Andean C. a. adustus (142 and 143) and C. $a$. leucocephalus (146), and a fifth clade included C. $c$. capucinus (117) and C. capucinus spp. (118), from Central America. Finally, there is a polytomy involving $C$. $a$. trinitatis (147) and C. o. brunneus (119 and 120).

The position of $C$. kaapori could not be determined. Despite grouping in all analyses with samples of $C$. olivaceus spp., this arrangement was not statistically supported.

\section{BioGeoBEARS biogeographical history}

According to BioGeoBEARS, the best-fit model explaining the biogeographical history of the capuchin monkeys was DEC $+\mathrm{J}$ (Table 2). The model shows that the ancestor of all capuchin monkeys had a wide distribution in South America, from the Atlantic Forest to different regions of the Amazon (Figure 5). The origin of both genera occurred through a sympatric speciation, indicating that Sapajus remained within the whole ancestral distribution, while Cebus was restricted along the West and North Amazon regions. This means that both gracile and robust capuchins were always present in the Amazon since their lineage split.

The biogeographic history of Sapajus was also directed by multiple and independent processes of sympatric speciation, with some lineages arising in the Atlantic Forest or Chaco in the early diversification of the genus, while other populations always remained with a wide distribution along the Cerrado, Atlantic Forest, Amazon and Chaco (Figure 5). Most recently ( 1.2 Ma, arrow 3, Figure 5), a sympatric speciation has given arise to the $S$. robustus lineage in the Atlantic Forest and to the "other" Sapajus lineage, that has a wide distribution in South America.

In the gracile capuchins, vicariance, expansion and founder events drove the diversification of the lineages through time. The initial diversification of Cebus occurred by a vicariance process between West and North Amazon. From the North Amazon, different diversification processes occurred reaching different regions. One lineage reached the Central America and Northern Andes by a founder-event in the early diversification of the genus $(\sim 2$ $\mathrm{Ma})$, followed by a recent return to the Northern Amazon.

Table 2 - Comparison among the estimated models in 'BioGeoBEARS'. For each implemented model in the analyses are shown: the log-likelihood values ( $\mathrm{LnL})$, number of parameters (n. params), dispersion, extinction, founder, and values of Akakie's Information Criteria (AIC and AIC weight).

\begin{tabular}{lccccccc}
\hline & LnL & n. params. & dispersion & extinction & founder & AIC & AIC weight \\
\hline DEC+J & -36.280 & 3 & 0.023 & $10^{-12}$ & 0.05 & 78.56 & 0.85 \\
DEC & -39.043 & 2 & 0.032 & $10^{-12}$ & 0.00 & 82.09 & 0.15 \\
BAYAREALIKE+J & -40.251 & 3 & 0.020 & $10^{-7}$ & 0.19 & 86.5 & 1.00 \\
DIVALIKE+J & -42.341 & 3 & 0.038 & $8.94^{-9}$ & 0.03 & 90.68 & 0.53 \\
DIVALIKE & -43.463 & 2 & 0.045 & $5.0^{-8}$ & 0.00 & 90.93 & 0.47 \\
BAYAREALIKE & -49.790 & 2 & 0.048 & $2.91^{-1}$ & 0.00 & 103.6 & 0.00 \\
\hline
\end{tabular}




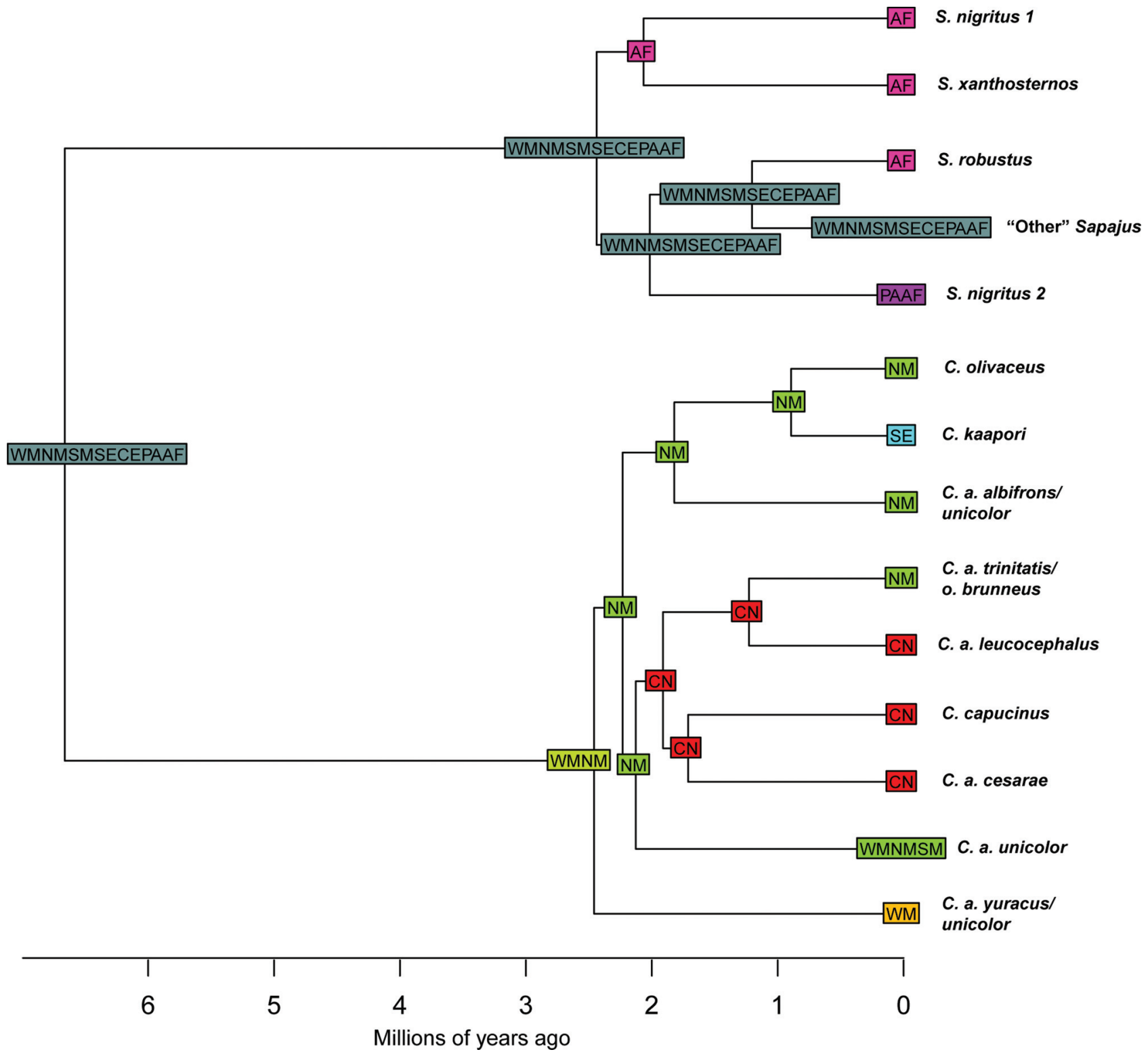

Figure 5 - DS2 time consensus tree with the estimates of ancestral areas of the capuchin monkeys made in 'BioGeoBEARS' through the DEC-J model. $\mathrm{CN}=$ Central America + North Andes; $\mathrm{WM}=$ West Amazon; $\mathrm{NM}=$ North Amazon + Coastal Venezuela; $\mathrm{SM}=$ South Amazon; $\mathrm{SE}=\mathrm{Southeast}$ Amazon; $\mathrm{CE}=$ Cerrado $\mathrm{PA}=$ Paraguay $/$ Argentina $; \mathrm{AF}=$ South and North Atlantic Forest.

Another lineage remained in the Amazon, reaching recently the Southeast Amazon also by a founder-event, and another one expanded its distribution to the South and West Amazon. The results of the BioGeoBEARS analyses with the four areas of Lima et al. (2017) was the same found by Lima et al. (2017) (Table S3 and Figure S1).

\section{Discussion}

\section{The origin of the capuchins}

As already suggested by different studies using different kinds of molecular markers, the capuchin monkeys constitute a monophyletic assemblage. However, the estimates of the capuchins origin provided by our data are slightly older than those proposed by Lynch Alfaro et al. (2012) and almost 1 Ma older than those found by Lima et al. (2017). Probably, the use of different markers is the reason for these differences.

Interestingly, the monophyly of Cebus and Sapajus could not be significantly recovered by all reconstruction analyses; while the BI and MP analyses recovered it, the ML analyzes did not. This can be explained by possible past introgression across these two lineages along their evolution, as shown in the mitochondrial markers used (Nascimento et al., 2015; Ruiz-García et al., 2016; Lima et al., 2017). As many other studies using multiple nuclear molecular markers have confirmed the monophyly of the gracile and robust capuchins, we do not consider that the lack of 
support in this study represents a real case of paraphyly for these genera (Perelman et al., 2011; Martins-Junior et al., 2015).

The timing of the origin of the capuchins during the late Miocene, around 6.8 Ma, is similar to that of other platyrrhines, such as the subgenus Saguinus sensu Garbino and Martins-Junior (2018) (Perelman et al., 2011; Buckner et al., 2015; Rylands et al., 2016), Ateles (Morales-Jimenez et al., 2015) and Alouatta (Cortés-Ortiz et al., 2003; Nascimento et al., 2005; Perelman et al., 2011). The origin of the two genera is more consistent with the relatively recent diversification of some lineages, such as Saimiri (Lynch Alfaro et al., 2015; Mercês et al., 2015), Callithrix (Schneider et al., 2012), Mico (Perelman et al., 2011; Schneider et al., 2012), Brachyteles and Lagothrix (Perelman et al., 2011; Di Fiori et al., 2015) and Callicebus and Cheracebus (Byrne et al., 2016).

\section{Phylogenetic and taxonomic implications in Cebus and Sapajus}

The phylogenetic analyses were unable to clarify the relationships among the different species (Figure 4). This strongly indicates that the evolution within Cebus and Sapajus probably resulted from an explosive process of diversification and dispersal between 2 and $3 \mathrm{Ma}$, as pointed out by several studies with this group (Casado et al., 2010; Boubli et al., 2012; Lynch Alfaro et al., 2012; Martins-Junior et al., 2015; Lima et al., 2017).

The evolution of the capuchins appears to have been far more complex than that of other platyrrhines, given that, in most cases, the Cyt $b$ and Control Region have been used successfully to confirm the monophyly of the species of several other genera (Bonvicino et al., 2001, 2003; Cortés-Ortiz et al., 2003; Nascimento et al., 2005; Babb et al., 2011; de Mello Martins et al., 2011; Botero et al., 2015; Morales-Jimenez et al., 2015; Lynch Alfaro et al., 2015). Even so, unresolved polytomies have also been found in most cases. Similar low levels of genetic differentiation have also been found in several vertebrate taxa distributed in both the Atlantic and Amazon forests (Costa, 2003; Santos et al., 2007; Cabanne et al., 2007; Casado et al., 2010; Martins-Junior et al., 2015).

An additional factor that may have enhanced the complexity of this process is the hybridization of lineages, both recent and ancient. The existence of extensive zones of contact between most species (Figure 1) strongly indicates that hybridization may have been frequent during the evolution of the lineages during the Pleistocene, a process that may be ongoing (Santos et al., 1987; Coimbra-Filho et al., 19911992; Silva Jr, 2001; Lynch Alfaro et al., 2012).

An important result of this study is that monophyly was not obtained for any of the species of robust capuchin monkeys. This situation is similar to the ones found by Casado et al. (2010), Ruiz-García et al. (2012) and Lima et al. (2017), also using mitochondrial genes. Lima et al. (2017), however, found support for the monophyly of $S$. nigritus and S. xanthosternos. Martins-Junior et al. (2015) also found a polytomic pattern in nuclear markers, indicating an explosive process of diversification during evolutionary history (Lynch Alfaro et al., 2012; Martins-Junior et al., 2015).

Our estimates were not able to establish the position of $S$. flavius within the clade, as indicated by arrow 3 in Figure 4. From the different phylogenetic criteria, its position varies in the topology. Even though $S$. flavius presents different characters that make it a full species (see Oliveira and Langguth, 2006), new studies must be made with more molecular markers to test its phylogenetic position.

The results of the current study agree with the findings of Casado et al. (2010), in relation to the formation of a monophyletic group composed by the $S$. cay specimens from Paraguay/Argentina, which are quite distinct from specimens from the Brazilian Cerrado, but which do not coalesce into a clade, suggesting that the taxon needs more attention. In addition to $S$. cay, a number of $S$. apella lineages were recovered without statistical support, and a very recent origin $(\sim 500 \mathrm{Ka})$, but without forming a single monophyletic group for the species. Ruiz-García et al. (2012) were also unable to separate the different $S$. apella subspecies into distinct clades. The authors show a strict relationship between $S$. cay (samples from Paraguay and Mato Grosso in Brazil) and S. macrocephalus suggesting the former as a subspecies of $S$. apella. They also found that the samples from Yungas in Bolivia-Argentina, classified by Silva Jr (2001) as $S$. cay, are more similar with samples of $S$. macrocephalus than the other putative $S$. cay. Casado et $a l$. (2010), using Cyt $b$, found only a subtle genetic difference between the $S$. cay and $S$. apella, with a polytomy between these lineages. More recently, Lima et al. (2017) could not recover the monophyly of $S$. apella, $S$. macrocephalus and $S$. cay. In their work, samples of $S$. cay from the Cerrado and Amazonia biomes in Mato Grosso and material from Paraguay are genetically very similar with samples of $S$. apella from southern Amazon in Mato Grosso and Rondonia in Brazil.

A very similar pattern was observed between $S$. apella and $S$. macrocephalus. Our results show no genetic differences between these two lineages, as have been shown in previous studies (Ruiz-García et al., 2012; Lynch Alfaro et al., 2012; Lima et al., 2017). Groves (2001) proposes that morphological differences between these two species are very small, mainly when $S$. macrocephalus is compared to $S$. apella fatuellus, indicating that macrocephalus may be a subspecies of $S$. apella. Silva Jr (2001) suggested that $S$. macrocephalus was a valid species, but mentioned several morphological similarities between it and S. apella. On the other hand, Ruiz-García et al. (2012), using genetic population and phylogenetic analysis, found that, even though $S$. macrocephalus and $S$. apella form different populations, the differences between them are too low to be split in two different species. This absence 
of genetic differences was also highlighted by Lima et al. (2017).

From a more conservative perspective, with the exception of $S$. xanthosternos and S. nigritus, most recognized species appear to have diverged within the past million years (arrow 3, Figure 4). This is a relatively short period of time for the establishment of synapomorphies among the distinct taxonomic entities (Casado et al., 2010), especially as the historical diversification process would have occurred in association with hybridization events. One consequence of this would be the enormous phenotypic diversity found in the robust capuchins (inter and intraspecifically), which may reflect the lack of an adequate time scale for the establishment of distinct morphological lineages. This, together with the findings from the two mitochondrial markers analyzed here, precludes the recognition of the different Sapajus species.

Even though Lima et al. (2017) used three mitochondrial markers and found monophyly for $S$. nigritus and $S$. xanthosternos, they did not use other phylogenetic methods to recover the monophyly of these species. In this context, the current evidence indicates that the diversity of robust capuchin species seems to be lower than the proposed by Silva Jr (2001). Here, considering all the morphological, biogeographical and genetic evidences discussed, we agree with the previous proposal by Ruiz-García et al. (2012), that $S$. cay and $S$. macrocephalus are junior synonyms of $S$. apella. Even with a biogeographical difference between $S$. cay and S. apella - the former occurring preferentially outside the Amazon - this study, as well as previous ones (Ruiz-Garcia et al., 2012; Lima et al., 2017), show that the two taxa are not differentiated with respect to traditional molecular markers. In the case of S. macrocephalus, in addition to genetic and morphological evidence, both it and $S$. apella occur continuously in the Amazon and the geographical boundaries between these two lineages are not well defined (Groves, 2001; Silva Jr, 2001). New studies with more molecular markers from nuclear and mitochondria or a genomic approach will certainly clarify this question. Morphologically, more studies involving geographic variation in pelage may show that the diagnostic pelage features of the traditionally recognized species correspond to a clinal variation.

It is interesting to note that in Cebus, a number of lineages did form well-supported clades (Figure 4), even though the evolutionary relationships among them were not well established. The preliminary analysis of the diversity of Cebu, done by Boubli et al. (2012) based on Cyt $b$ and Control Region and using a pure BI analysis pointed to the existence of six groups and a total of 12 species, challenging the accepted arrangement (C. albifrons, $C$. olivaceus, $C$. kaapori and C. capucinus). This proposal was accepted partially by Rylands and Mittermeier (2013), who proposed 14 Cebus species.

However, none of the groups proposed by Boubli et al. (2012) were recovered with adequate statistical support in the current study, although some findings were concordant. For example, the specimens of C. a. albifrons formed a monophyletic group, while $C$. a. leucocephalus and $C$. $a$. adustus coalesced into a monophyletic group, indicating that these two forms do, in fact, represent a single subspecies. Similarly, the samples of C. o. brunneus and C. $a$. trinitatis also formed a monophyletic, indicating that they form a single taxonomic unit.

Some authors suggest that $C$. a. trinitatis, from Trinidad Tobago Island, could have originated from an ancestral population of $C$. albifrons from the Venezuelan Andes (Boubli et al., 2012). Others suggest that these animals were introduced in the island by humans from Venezuelan populations of C. olivaceus (Long, 2003). However, the clear morphological distinctions between $C$. a. trinitatis and C. o. brunneus highlighted when specimens from museums or from the wild are compared, make this grouping unexpected. New studies with more samples are necessary to clarify this question.

The C. a. cesarae clade was also supported statistically. The position of $C$. kaapori is still controversial, with some authors proposing it as a subspecies of $C$. olivaceus (Rylands et al., 2000), and others considering it a full species (Groves, 2001; Silva Jr, 2001). Even though our analyses agree with Lima et al. (2017), grouping C. kaapori with some $C$. olivaceus lineages, this arrangement had no statistical support (Figure 4).

Overall, the lack of any clear monophyly in the different species, together with clear polytomy of the different Cebus lineages, restricts any conclusive interpretation of the different arrangements proposed for the Cebus species. In the absence of well-supported evidence, we suggest the continued use of the conventional taxonomic arrangement currently used by most authors (C. albifrons, C. olivaceus, C. kaapori and C. capucinus) instead of the proposal by Boubli et al. (2012), at least until additional mitochondrial, and principally, nuclear markers are analyzed.

\section{Not a recent but an old sympatric event explains the current sympatry between gracile and capuchin monkeys}

The most important result obtained in the current research is that Cebus and Sapajus arose at $\sim 6.8 \mathrm{Ma}$ from a sympatric event, with both genera occurring in the Amazon since their origin (Figure 5). Furthermore, both genera have always been present in the Amazon throughout their biogeographic history. It means that the current sympatry observed between gracile and robust capuchins in the Amazon is explained by an ancestral distribution of these two lineages, supporting the Sympatric Evolution (SEV) hypothesis. It is an important finding because the currently accepted hypothesis based on previous studies is the Reinvasion of the Amazon (Lynch Alfaro et al., 2012; Lima et al., 2017), which states that only recently have the robust capuchins colonized the Amazon basin. In none of 
the previous studies a scenario of sympatric evolution was considered.

Lima et al. (2017) found that the ancestral capuchins had a wide distribution throughout South America, from the Amazon to the Atlantic Forest. These authors also suggest that the formation of the Cerrado $(4-8 \mathrm{Ma})$ was the geographical barrier responsible for the vicariant origin of Cebus and Sapajus, with the former restricted to the Amazon and the latter to the Atlantic Forest. Our results agree with this wide distribution of ancestral capuchins. However, even if the Cerrado has had an important role in the origin of these two genera, it was not a geographical barrier for them, since they arose by a sympatric process in the Amazon, with Sapajus widespread across all South American regions and Cebus restricted to North and West Amazon (Figure 5).

In the case of the historical biogeography of Sapajus, strong discrepancies were found here when compared to the results of Lima et al. (2017). The latter authors found that Sapajus was restricted to the Atlantic Forest along most of its evolutionary history and only recently (at c. 500 $\mathrm{Ka}$ ) expanded their distribution to the Cerrado, Chaco and Amazon regions. In contrast, our analyses do not support this proposal, but show that the robust capuchins always had a wide distribution across these different biomes, and that the origin of the distinct lineages occurred by multiple and independent sympatric events (Figure 5).

In the recovered topologies, the grouping of S. apella samples from both banks of the Amazon rivers (Figure 4) suggest that these rivers were and are not geographical barriers for these primates, contrary what has been observed for other Platyrrhini groups (Vallinoto et al., 2006; Couette, 2007; Boubli et al., 2015; Lynch Alfaro et al., 2015; Mercês et al., 2015). This result agrees with the finds of Lima et al. (2017). This can be explained by the wide ancestral and continued distribution of Sapajus across different regions of the Amazon (Figure 5). Furthermore, it suggests that throughout the evolution of the genus there was gene flow between robust capuchin populations from different river banks.

It is important to note that these discrepancies between our results and those found by Lima et al. (2017) are explained by the use of different geographical areas (Figure 5, Figure S1 and Table S3). While the analysis in BioGeoBEARS with the eight areas from Lynch Alfaro et al. (2012) corroborate the Sympatric Evolution Hypothesis, the analysis with four areas proposed by Lima et al. (2017) support the Reinvasion of the Amazon Hypothesis. Although this weakens our result of a sympatric origin for Cebus and Sapajus, it also shows that the historical biogeography of the capuchin monkeys is still in debate, as the data from both the present study and the one by Lima et al. (2017) do not satisfactorily solve this question. This also shows that the scientific community should be careful in defining the biogeographic areas for the BioGeoBEARS analyses, especially if the data is not phylogenetically strong.

Regarding Cebus, the analyses support the proposal of Lynch Alfaro et al. (2012) and Lima et al. (2017) for an Amazon origin of the gracile capuchins (Figures 4 and 5). In fact, it appears that Cebus has experienced different kinds of diversification processes along its evolutionary history. While the diversification of Sapajus was driven by sympatric speciation, after an initial vicariance event, Cebus experienced founder and range expansion events. In their early diversification $(\sim 2 \mathrm{Ma})$, the gracile capuchins crossed the Amazon river southward into the South Amazon, and crossed the Andes northwards reaching Central America. In contrast, it seems that the Tocantins river was a strong barrier for this group, since Cebus reached the Southeast Amazon basin only recently (Figure 5). Our results agree with those found by Lima et al. (2017) about the incursion into Central America by gracile capuchin monkeys at $\sim 2 \mathrm{Ma}$, after the complete elevation of the Andes and the closure of the Panama Isthmus (Hoorn et al., 2010).

Three important questions remain to be answered: Which of the biogeographical hypotheses for capuchins evolution is more plausible: Sympatric Evolution (SE) or Reinvasion of the Amazon (ROA)? When and which putative routes were used by gracile capuchins to cross the Andes Cordillera? Why did Sapajus even come to exist in the Amazon, since by its origin it could not cross the Andes? Certainly, new studies with samples from these key regions and using more molecular markers, mainly NGS data, will reveal which is the most likely phylogeographical scenario.

\section{Acknowledgments}

Funding for this research was provided by $\mathrm{CNPq}$ (grants 306416/2013-1 to IS, and 304684/2013-9) and CAPES Program No. 3296/2013-PROAM to HS. We are thankful for the valuable contributions of the two reviewers of this manuscript.

\section{References}

Alfaro JWL, Silva JDESE and Rylands AB (2012) How different are Rrobust and gracile capuchin monkeys? An argument for the use of Sapajus and Cebus. Am J Primatol 74:273286.

Ashley MV and Vaughn JL (1995) Owl monkeys (Aotus) are highly divergent in mitochondrial cytochromec oxidase (COII) sequences. Int J Primatol 16:793-806.

Babb PL, Fernandez-Duque E, Baiduc CA, Gagneux P, Evans S and Schurr TG (2011) mtDNA diversity in Azara's owl monkeys (Aotus azarai azarai) of the argentinean Chaco. Am J Phys Anthropol 146:209-224.

Bonvicino CR, Lemos B and Seuánez HN (2001) Molecular phylogenetics of howler monkeys (Alouatta, Platyrrhini): A comparison with karyotypic data. Chromosoma 110:241-246.

Bonvicino CR, Boubli JP, Otazú IB, Almeida FC, Nascimento FF, Coura JR and Seuánez HN (2003) Morphologic, karyotypic, 
and molecular evidence of a new form of Chiropotes (Primates, Pitheciinae). Am J Primatol 61:123-133.

Botero S, Stevenson PR and Di Fiori A (2015) A primer on the phylogeography of Lagothrix lagotricha (sensu Fooden) in northern South America. Mol Phylogenet Evol 82:511-517.

Boubli JP, Rylands AB, Farias IP, Alfaro ME and Alfaro JL (2012) Cebus phylogenetic relationships: A preliminary reassessment of the diversity of the untufted capuchin monkeys. Am J Primatol 74:381-393.

Boubli JP, Ribas C, Alfaro JWL, Alfaro ME, Silva MNF, Pinho GM and Farias IP (2015) Spatial and temporal patterns of diversification on the Amazon: A test of the riverine hypothesis for all diurnal primates of Rio Negro and Rio Branco in Brazil. Mol Phylogenet Evol 82:400-412.

Buckner JC, Alfaro JWL, Rylands AB and Alfaro ME (2015) Biogeography of the marmosets and tamarins (Callitrichidae). Mol Phylogenet Evol 82:413-425.

Bush MB (1994) Amazonian speciation: A necessarily complex model. J Biogeogr 21:5-17.

Byrne H, Rylands AB, Carneiro JC, Alfaro JWL, Bertuol F, Silva MNF, Messias M, Groves CP, Mittermeier RA, Farias I, et al. (2016) Phylogenetic relationships of the New World titi monkeys (Callicebus): First appraisal of taxonomy based on molecular evidence. Front Zool 13:10.

Cabanne GS, Santos FR and Miyaki CY (2007) Phylogeography of Xiphorhynchus fuscus (Passeriformes, Dendrocolaptidae): Vicariance and recent demographic expansion in southern Atlantic Forest. Biol J Linn Soc 91:73-84.

Casado F, Bonvicino CR, Nagle C, Comas B, Manzur TD, Lahoz MM and Seuánez HN (2010) Mitochondrial divergence between 2 populations of the hooded capuchin, Cebus (Sapajus) cay (Platyrrhini, Primates). J Hered 101:261-269.

Coimbra-Filho AF, Rylands AB, Pissinatti A and Santos IB (1991-1992) The distribution and status of the buff-headed capuchin monkey, Cebus xanthosternos Wied 1820, in the Atlantic Forest region of Eastern Brazil. Primate Conserv 12-13:24-30.

Colinvaux PA, Oliveira PE and Bush MB (2000) Amazonian and Neotropical plant communities on glacial timescales: The failure of the aridity and refuge hypotheses. Quart Sci Rev 191:141-169.

Cortés-Ortiz L, Bermingham E, Rico C, Rodriguez-Luna E, Sampaio I and Ruiz-Garcia M (2003) Molecular systematics and biogeography of the Neotropical monkey genus, Alouatta. Mol Phylogenet Evol 26:64-81.

Costa LP (2003) The historical bridge between the Amazon and the Atlantic Forest of Brazil: A study of molecular phylogeography with small mammals. J Biogeogr 30:71-86.

Couette S (2007) Différenciation morphologique et génétique des populations de douroucoulis (Aotus infulatus, Primates, Platyrhiniens, Cebidae) provenant des rives droite et gauche du rio Tocantins (Brésil). C R Biol 330:148-158.

de Mello Martins F, Gifalli-Iughetti C, Koiffman, CP and Harris EE (2011) Coalescent analysis of mtDNA indicates Pleistocene divergence among three species of howler monkeys (Alouatta spp.) and population subdivision within the Atlantic Coastal Forest species, A. guariba. Primates 52:77-87.

de Thoisy B, Silva AG, Ruiz-García M, Tapia A, Ramirez O, Arana M, Quse V, Paz-y-Miño C, Tobler M, Pedraza C and Lavergne A (2010) Population history, phylogeography, and conservation genetics of the last Neotropical mega- herbivore, the lowland tapir (Tapirus terrestris). BMC Evol Biol 10:278.

Di Fiori A, Chave PB, Cornejo FM, Schmitt CA, Shanee S, Cortés-Ortiz L, Fagundes V, Roos C and Pacheco V (2015) The rise and fall of a genus: Complete mtDNA genomes shed light on the phylogenetic position of yellow-tailed woolly monkeys, Lagothrix flavicauda, and on the evolutionary history of the family Atelidae (Primates: Platyrrhini). Mol Phylogenet Evol 82:495-510.

Drummond AJ, Suchard MA, Xie D and Rambaut A (2012) Bayesian phylogenetics with BEAUti and the BEAST 1.7. Mol Biol Evol 29:1969-1973.

Feijó A and Langguth A (2013) Mamíferos de médio e grande porte do Nordeste do Brasil: Distribuição e taxonomia, com descrição de novas espécies. Rev Nordest Biol 22:3-225.

Fuchs J, Chen S, Johnson JA and Mindell DP (2011) Pliocene diversification within the South American forest falcons (Falconidae: Micrastur). Mol Phylogenet Evol 60:398-407.

Fuchs J, Johnson JA and Mindell DP (2015) Rapid diversification of falcons (Aves: Falconidae) due to expansion of open habitats in the Late Miocene. Mol Phylogenet Evol 82:166-182.

Garbino GST (2015) Defining genera of New World monkeys: The need for a critical view in a necessarily arbitrary task. Int J Primatol 36:1049-1046.

Garbino GST and Martins-Junior AMG (2018) Phenotypic evolution in marmoset and tamarin monkeys (Cebidae, Callitrichinae) and a revised genus-level classification. Mol Phylogenet Evol 118:156-171.

Goloboff P (1999) Analyzing large data sets in reasonable times: Solutions for composite optima. Cladistics 15:415-428.

Goloboff PA and Catalano SA (2016) TNT version 1.5, including a full implementation of phylogenetic morphometrics. Cladistics 32:221-238.

Groves C (2001) Primate Taxonomy. Smithsonian, Washington, $350 \mathrm{p}$.

Haffer J (2008) Hypothesis to explain the origin of species in Amazonia. Braz J Biol 68:917-947.

Hayes FE and Sewlal JAN (2004) The Amazon River as a dispersal barrier to passerine birds: Effects of river width, habitat and taxonomy. J Biogeogr 31:1809-1818.

Hershkovitz P (1949) Mammals of northern Colombia. Preliminary report No. 4: monkeys (Primates), with taxonomic revisions of some forms. Proc U S Nat Mus 98:323-427.

Hershkovitz P (1970) Notes on Tertiary platyrrhine monkeys and description of a new genus from the late Miocene of Colombia. Folia Primatol 12:1-37.

Hoorn C, Wesselingh FP, ter Steege H, Bermudez MA, Mora A, Sevink J, Sanmartín I, Sanchez-Meseguer A, Anderson CL, Figueiredo JP, et al. (2010) Amazonia through time: Andean uplift, climate change, landscape evolution, and biodiversity. Science 330:927-931.

Irwin DM, Kocher TD and Wilson AC (1991) Evolution of the cytochrome $b$ gene of mammals. J Mol Evol 32:82-102.

Kay RF (1994) "Giant" tamarin from the Miocene of Colombia. Am J Phys Anthropol 95:333-353.

Kay RF, Madden RH, Plavcan JM, Cifelli RL and Guerrero-Diaz J (1987) Stirtonia victoriae, a new species of Miocene Colombian primate. J Hum Evol 16: 173-196.

Kay RF, Johnson DJ and Meldrum DJ (1998) A new pitheciin primate from the middle Miocene of Argentina. Am J Primatol 45:317-336. 
Lanfear R, Calcott B, Ho SYW and Guidon S (2012) PartitionFinder: Combined selection of partitioning schemes and substitution models for phylogenetic analyses. Mol Biol Evol 29:1695-1701.

Larkin M, Blackshields G, Brown N, Chenna R, McGettigan P, McWilliam H, Valentin F, Wallace I, Wilm A and Lopez R (2007) Clustal W and Clustal X version 2.0. Bioinformatics, 23:2947-2948.

Lima MGM, Buckner JC, Silva-Jr JS, Aleixo A, Martins AB, Boubli JP, Link A, Farias IP, Silva MN, Röhe F, et al. (2017) Capuchin monkey biogeography: Understanding Sapajus Pleistocene range expansion and the current simpatry between Cebus and Sapajus. J Biogeogr 44:810-820.

Long JL (2003) Introduced Mammals of the World: Their history, distribution and influence. CSIRO Publishing, Collingwood, $589 \mathrm{p}$.

Lynch Alfaro JW, Boubli JP, Olson LE, Di Fiore A, Wilson B, Gutiérrez-Espeleta GA, Chiou KL, Schulte M, Neitzel S, Ross V, et al. (2012) Explosive Pleistocene range expansion leads to widespread Amazonian sympatry between robust and gracile capuchin monkeys. J Biogeogr 39:272-288.

Lynch Alfaro JW, Boubli JP, Paim FP, Ribas CC, Silva MNF, Messias MR and Farias IP (2015) Biogeography of squirrel monkeys (genus Saimiri): South-central Amazon origin and rapid pan-Amazonian diversification of a lowland primate. Mol Phylogenet Evol 82:436-454.

Martins FM, Templeton AR, Pavan ACO, Kohlbach BC and Morgante JS (2009) Phylogeography of the commom vampire bat (Desmodus rotundus): marked population structure, Neotropical Pleistocene vicariance and incongruence between nuclear and mtDNA markers. BMC Evol Biol 9:294.

Martins FM, Gifalli-Iughett C, Koiffman CP and Harris EE (2011) Coalescent analysis of mtDNA indicates Pleistocene divergence among three species of howler monkey (Alouatta spp.) and population subdivision within the Atlantic Coastal Forest species, A. guariba. Primates 52:77-87.

Martins-Junior AM, Amorim N, Carneiro JC, de Mello Affonso PRA, Sampaio I and Schneider H (2015) Alu elements and the phylogeny of capuchin (Cebus and Sapajus) monkeys. Am J Primatol 77:368-375.

Matauschek C, Roos C and Heymann EW (2011) Mitochondrial phylogeny of tamarins (Saguinus, Hoffmannsegg 1807) with taxonomic and biogeographic implications for the $S$. nigricollis species group. Am J Phys Anthropol 144:564574.

Matzke N (2013) 'BioGeoBEARS': biogeography with Bayesian (and likelihood) evolutionary analysis in R scripts. University of California, Berkeley, R package, version 3.3.3.

Matzke N (2014) Model selection in historical biogeography reveals that founder-event speciation is a crucial process in Island Clades. Syst Biol 63:951-970.

Mercês MP, Alfaro JWL, Ferreira WAS, Harada ML and Silva Jr JS (2015) Morphology and mitochondrial phylogenetics reveal that the Amazon river separates two eastern squirrel monkey species: Saimiri sciureus and S. collinsi. Mol Phylogenet Evol 82:426-435.

Morales-Jimenez AL, Disotell T and Di Fiori A (2015) Revisiting the phylogenetic relationships, biogeography, and taxonomy of spider monkeys (genus Ateles) in light of new molecular data. Mol Phylogenet Evol 82:467-483.
Nascimento F, Bonvicino C, Da Silva F, Schneider M and Seuánez H (2005) Cytochrome $b$ polymorphisms and population structure of two species of Alouatta (Primates). Cytogenet Genome Res 108:106-111.

Nascimento FF, Lazar A, Seuánez HN and Bonvicino CR (2015) Reanalysis of the biogeographical hypothesis of range expansion between robust and gracile capuchin monkeys. J Biogeogr 42:1349-1357.

Nelson BW, Ferreira CAC, Silva MF and Kawasaki ML (1990) Endemism centres, refugia and botanical collection density in Brazilian Amazonia. Nature 345:714-716.

Oliveira C, Gaiotto F, Costa M and Martinez R (2011) Molecular genetic analysis of the yellow-breasted capuchin monkey: recommendations for ex situ conservation. Genet Mol Res 10:1471-1478.

Oliveira MM and Langguth A (2006) Rediscovery of Marcgrave's capuchin monkey and designation of a neotype for Simia flavia Schreber, 1774 (Primates, Cebidae). Bol Mus Nac Rio de Janeiro: Zool 523:1-16.

Perelman P, Johnson WE, Roos C, Seuánez HN, Horvath JE, Moreira MAM, Kessing B, Pontius J, Roelke M, Rumpler Y, et al. (2011) A molecular phylogeny of living primates. PLoS Genet 7:e1001342.

Ribas CC, Gaban-Lima R, Miyaki CY and Cracraft J (2005) Historical biogeography and diversification within the Neotropical parrot genus Pionopsitta (Aves: Psittacideae). J Biogeogr 32:1409-1427.

Ribas CC, Aleixo A, Nogueira ACR, Miyaki CY and Cracraft J (2012) A palaeobiogeographic model for biotic diversification within Amazonia over the past three million years. Proc R Soc B 279:681-689.

Rosenberger AL (2012) New World Monkey nightmares: Science, art, use, and abuse (?) in platyrrhine taxonomic nomenclature. Am J Primatol 74:692-695.

Rosenberger AL, Hartwig WC, Takai M, Setoguchi T and Shigehara N (1991) Dental variability in Saimiri and the taxonomic status of Neosaimiri fieldsi, an early squirrel monkey from La Venta, Colombia. Int J Primatol 12:291-302.

Ruiz-García M, Vásquez C, Camargo E, Leguizamón N, Gálvez H, Vallejo A, Pinedo M, Castellanos-Mora L, Shostell J and Alvarez D (2011) Molecular phylogenetics of Aotus (Platyrrhini, Cebidae). Int J Primatol 32:1218-1241.

Ruiz-García M, Castillo MI, Lichilin-Ortiz N and Pinedo-Castro M (2012) Molecular relationships and classification of several tufted capuchin lineages (Cebus apella, Cebus xanthosternos and Cebus nigritus, Cebidae), by means of mitochondrial cytochrome oxidase II gene sequences. Folia Primatol 83:100-125.

Ruiz-García M, Castillo MI and Luengas-Villamil K (2016) Is it misleading to use Sapajus (robust capuchins) as a genus? A review of the evolution of the capuchins and suggestions on their systematics. In: Ruiz-Garcia M and Shostell JM (eds) Phylogeny, molecular population genetics, evolutionary biology and conservation of the Neotropical primates. Nova Science Publisher Inc., New York, pp 209-268.

Rull V (2008) Speciation timing and neotropical biodiversity: The Tertiary-Quaternary debate in the light of molecular phylogenetic evidence. Mol Ecol 17:2722-2729.

Rylands AB, Schneider H, Langguth A, Mittermeier RA, Groves CP and Rodríguez-Luna E (2000) An assessment of the di- 
versity of New World primates. Neotropical Primates 8:6193.

Rylands AB and Mittermeier RA (2013) Family Cebidae (squirrel monkeys and capuchins). In: Mittermeier RA, Rylands AB and Wilson DE (eds) Handbook of the Mammals of the World, Vol 3, Primates. Lynx Edicions, Barcelona, pp 348-413.

Rylands AB, Heymann EW, Lynch Alfaro J, Buckner JC, Roos C, Matauschek C, Boubli JP, Sampaio R and Mittermeier RA (2016) Taxonomic review of the New World tamarins (Primates: Callitrichidae). Zool J Linn Soc 177:1003-1028.

Santos AMM, Cavalcanti DR, Silva JMC and Tabarelli M (2007) Biogeogaphical relationships among tropical forests in north-eastern Brazil. J Biogeogr 34:437-446.

Santos IB, Mittermeier RA, Rylands AB and Valle CMC (1987) The distribution and conservation status of Primates in southern Bahia, Brazil. Primate Conserv 8:126-142.

Schneider H and Sampaio I (2015) The systematics and evolution of New World primates-A review. Mol Phylogenet Evol 82:348-357.

Schneider H, Bernardi JAR, Cunha DB, Tagliaro CH, Vallinoto M, Ferrari SF and Sampaio I (2012) A molecular analysis of the evolutionary relationships in the Callitrichinae, with emphasis on the position of the dwarf marmoset. Zool Scr 41:1-10.

Silva Júnior JS (2001) Especiação nos macacos-prego e caiararas, gênero Cebus Erxleben, 1777 (Primates, Cebidae). D. Sc. Thesis, Universidade Federal do Rio de Janeiro, Rio de Janeiro, $377 \mathrm{p}$.

Smith MF and Patton JL (1993) Diversification of South American muroid rodents: Evidence from mitochondrial DNA sequence data for the Akodontine tribe. Biol J Linn Soc 50:149-177.

Sousa-Neves T, Aleixo A and Sequeira F (2013) Cryptic patterns of diversification of a widespread Amazonian woodcreeper species complex (Aves: Dendrocolaptidae) inferred from multilocus phylogenetic analysis: implications for historical biogeography and taxonomy. Mol Phylogenet Evol 68:410424.

Stamatakis A (2014) RAxML version 8: A tool for phylogenetic analysis and post-analysis of large phylogenies. Bioinformatics 30:1312-1313.

Takai M (1994) New specimens of Neosaimiri fieldsi, a middle Miocene ancestor of the squirrel monkeys from La Venta, Colombia. J Hum Evol 27:329-360.

Vallinoto M, Araripe J, do Rego PS, Tagliaro CH, Sampaio I and Schneider H (2006) Tocantins river as an effective barrier to gene flow in Saguinus niger populations. Genet Mol Biol 29:215-219.

\section{Internet Resources}

IUCN (2016) IUCN red list of threatened species. Version 2016.1, http://www.iucnredlist.org/.

Müller J, Müller KF, Neinhuis C and Quandt D (2010) PhyDE Phylogenetic Data Editor, http://www.phyde.de/.

\section{Supplementary material}

The following online material is available for this article:

Figure S1 - DS2 time consensus tree with the estimates of ancestral areas of the capuchin monkeys considering the four areas proposed by Lima et al. (2017).

Table S1 - List of species with their respective samples, codes, ID.

Table S2 - Characteristics of the datasets.

Table S3 - Comparison among the estimated models in 'BioGeoBEARS' considering the four areas.

Methods Appendix S1 - Methods used in 'BioGeoBEARS' with the four areas from Lima et al. (2017).

$$
\text { Associate Editor: Louis Bernard Klaczko }
$$

License information: This is an open-access article distributed under the terms of the Creative Commons Attribution License (type CC-BY), which permits unrestricted use, distribution and reproduction in any medium, provided the original article is properly cited. 